\title{
$\begin{aligned} & \text { XVII Simpósio Brasileiro } \\ & \text { de Geografia Fisica Aplicada }\end{aligned}$
$\begin{aligned} & \text { I Congresso Nacional } \\ & \text { de Geografia Física }\end{aligned}$
}

\section{O USO E OCUPAÇÃO DA TERRA NO SETOR NORTE DA ÁREA URBANA DE PATOS DE MINAS (MG): DESTAQUE AS ÁREAS DE PRESERVAÇÃO PERMANENTE (APPS)}

\author{
Daiane Casagrande ${ }^{(\mathrm{a})}$, Rayanne Lina Bicalho ${ }^{(\mathrm{b})}$, Juliana A. C. Petronzio ${ }^{(\mathrm{c})}$, Alan Silveira ${ }^{(\mathrm{d})}$ \\ (a) Discente do Curso de Geologia, Universidade Federal de Uberlândia, daianecasagrande 7 @ hotmail.com \\ (b)Discente do Curso de Geologia, Universidade Federal de Uberlândia, rayanne.bicalho@ufu.br \\ (c) Técnica do Curso de Geologia, Universidade Federal de Uberlândia - IG, julianapetronzio@gmail.com \\ (d) Docente do Curso de Geologia, Universidade Federal de Uberlândia- IG, alan.silveira@ufu.br
}

\section{Eixo: Uso e ocupação das Terras e legislação ambiental}

\begin{abstract}
Resumo
O trabalho tem interesse em verificar as condições de uso e ocupação da Terra no setor norte da cidade de Patos de Minas (MG), destacando as Áreas de Preservação Permanente (APPs) dos afluentes do ribeirão Limoeiro. Procura colaborar com informações que subsidiem o Plano Diretor do futuro campus UFU Patos de Minas. Apresentou três fases de desenvolvimento: referencial bibliográfico, mapeamento e trabalho de campo. Pode-se registrar que parte das APPs não preservam os limites de trinta e cinquenta metros de vegetação, como indica o "Novo" Código Florestal (BRASIL, 2012). Tal retirada da vegetação contribui para o desenvolvimento de processos denudativos, como um voçorocamento ilustrado, posicionado em cabeceira de drenagem de afluente do ribeirão Limoeiro.
\end{abstract}

Palavras chave: Áreas de Preservação Permanente (APPs). Patos de Minas (MG). processos erosivos.

\section{Introdução}

Posicionado na latitude $18^{\circ} 34^{\prime}$ '44" S e longitude $46^{\circ} 31^{\prime}$ "05" W, o Município de Patos de Minas está inserido na Mesorregião do Triângulo Mineiro e Alto Paranaíba (IBGE, 2010). Esta é composta por 66 municípios onde vivem cerca de 2,2 milhões de pessoas. A cidade de Patos de Minas, com estimados 149.856 habitantes (IBGE, 2016), é a terceira cidade mais populosa da Mesorregião e apresenta em seu setor norte, um vetor de expansão urbana (figura 1).

Este setor norte de expansão urbana é drenado pelo ribeirão Limoeiro, afluente da margem direita do rio Paranaíba. Em setor de topo e alta vertente de afluentes do ribeirão Limoeiro, será instalada uma unidade da Universidade Federal de Uberlândia (UFU) (figura 1). Assim, este trabalho apresenta resultados do Projeto Técnico de Caracterização dos Aspectos Físico-Ambientais do Campus UFU. Tais resultados associados às condições de uso e ocupação da terra do setor norte da cidade, com destaque as Áreas de Preservação Permanente (APPs) dos afluentes do ribeirão Limoeiro, procuram colaborar como um dos instrumentos de subsídio ao Plano Diretor do futuro campus. O trabalho tem, portanto, o objetivo verificar as condições das APPs em afluentes do ribeirão Limoeiro, tendo em vista que esses canais circundam o futuro campus UFU Patos de Minas. 


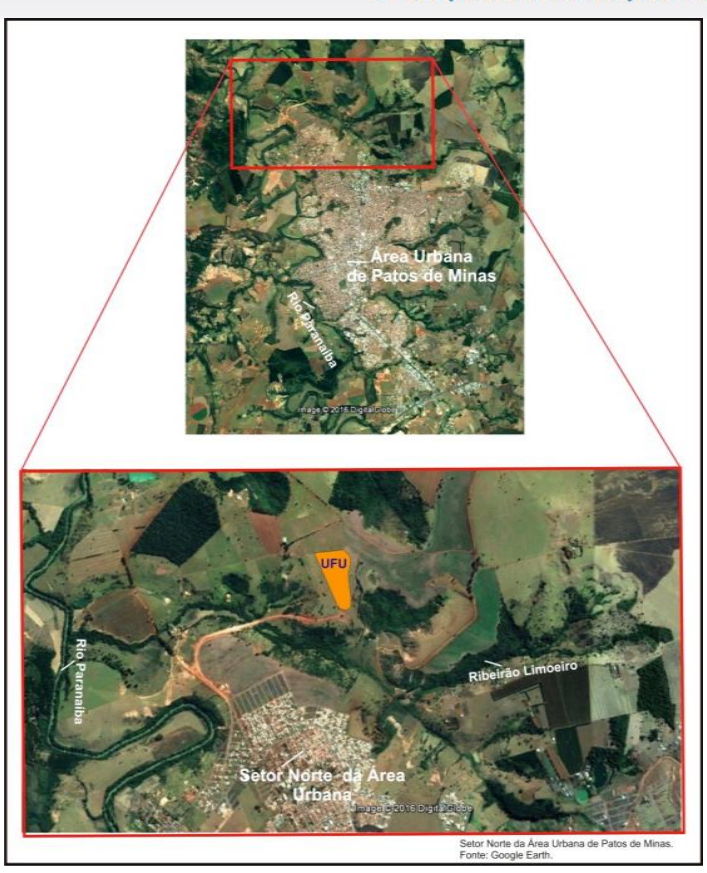

Figura 1: Área urbana de Patos de Minas, com destaque ao setor norte da cidade, drenada pela bacia do ribeirão Limoeiro. Organização: Autores.

\section{Metodologia}

O desenvolvimento do trabalho ocorreu em três fases, a saber: a primeira constitui no levantamento bibliográfico básico sobre o tema pesquisado; a segunda, dedicou-se a elaboração do mapeamento de cobertura vegetal e uso da terra nas áreas destinadas as APPs; e a terceira, correspondeu a reambulação das informações em campo. Este mapa, desenvolvido em uma escala de desenho de 1:12.000, foi organizado no sistema de Projeção UTM/ Datum WGS 84, fuso 23 sul, com uso da ferramenta software ArcGis 10.2, auxiliado pelo Google Earth, o qual forneceu imagens para interpretações visuais. Os elementos de fotointerpretação presentes nas imagens são demonstrados no quadro 1.

As áreas de APP's foram organizadas por meio da construção de buffers de 30 metros para os canais fluviais e buffers de 50 metros para as nascentes, considerando a Lei Federal 12.651/2012 - "Novo" Código Florestal (BRASIL, 2012), que dispõe sobre a proteção da vegetação nativa e que revogou a Lei 4.771/1965. Foram considerados os seguintes critérios legais: 
Quadro 1: Classes da Cobertura Vegetal e Uso da Terra em Áreas de APPs - Bacia do Ribeirão Limoeiro, setor norte da área urbana de Patos de Minas Fonte: Google Earth. Organização: Petronzio (2016).

\begin{tabular}{|c|c|}
\hline Classes & Comportamento Espectral \\
\hline Avea Urtana & \\
\hline Area Nagata & \\
\hline Agricultura & \\
\hline Pastagem & \\
\hline Cobertura Vegetal & \\
\hline & \\
\hline
\end{tabular}

Art. 4 Considera-se Área de Preservação Permanente, em zonas rurais ou urbanas, para os efeitos desta Lei:

I - as faixas marginais de qualquer curso d'água natural perene e intermitente, excluídos os efêmeros, desde a borda da calha do leito regular, em largura mínima de:

a) 30 (trinta) metros, para os cursos d'água de menos de 10 (dez) metros de largura;

IV - as áreas no entorno das nascentes e dos olhos d'água perenes, qualquer que seja sua situação topográfica, no raio mínimo de 50 (cinquenta) metros (BRASIL, 2012, grifo nosso).

\section{Resultados e Discussões}

As APPs delimitadas pertencem aos canais e nascentes da bacia hidrográfica do ribeirão Limoeiro, a qual posiciona-se no setor norte da cidade de Patos de Minas e que abrigará a nova unidade universitária da UFU (setor de topo e alta vertente de afluentes do ribeirão Limoeiro). Observou-se a partir do processo de mapeamento e interpretação visual, e posteriormente por checagem em campo, que parte das APPs não estão de acordo com o previsto no "Novo" Código Florestal, ou seja, não obedecem aos limites de trinta e cinquenta metros de áreas de preservação permanente, conforme pode ser visto na figura 2. 

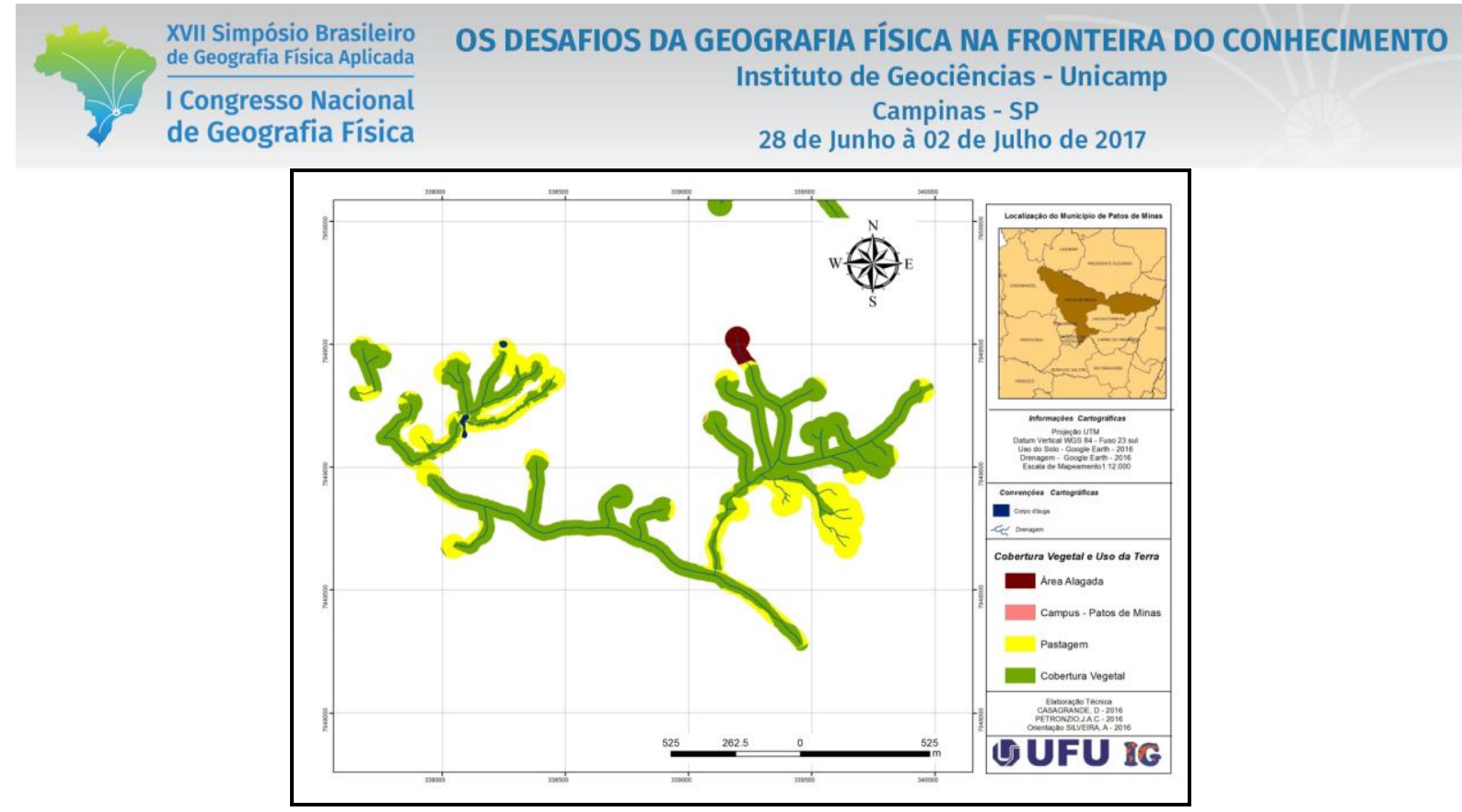

Figura 2: Mapa de APPs de afluentes do ribeirão Limoeiro - Patos de Minas (MG). Organização: Petronzio (2016).

O quadro 2 apresenta os valores das áreas e seus respectivos percentuais encontrados no registro cartográfico de cobertura vegetal e uso da terra:

Quadro 2: Valores e percentuais de cobertura vegetal e uso da Terra na áreas de APPs. Organização: Autores.

\begin{tabular}{|c|c|c|}
\hline Classes & Áreas em km $\mathbf{~}^{\mathbf{2}}$ & Porcentagem (\%) \\
\hline Campus UFU Patos de Minas & 0,00025 & 0,03 \\
\hline Área Alagada & 0,02 & 2,17 \\
\hline Pastagem & 0,18 & 19,51 \\
\hline Vegetação Natural & 0,72 & 78,29 \\
\hline Total & $\mathbf{0 , 9 2 0 4 2}$ & $\mathbf{1 0 0}$ \\
\hline
\end{tabular}

Nota-se que os valores da pastagem correspondem à $0,18 \mathrm{~km}^{2}$ do total de $0.92 \mathrm{~km}^{2}$ de APPs, identificando a forte presença do pisoteio do gado, o que corrobora para a degradação dessas áreas de preservação. Como exemplo, destaca-se um setor de cabeceira de drenagem onde foi registrado a presença de um voçorocamento. Esta feição denudativa (foto 1), está associada a fragilidade do material rochoso, a concentração do escoamento superficial, bem como a dinâmica de uso e ocupação da terra, com o marcante pisoteio do gado (foto 2). 


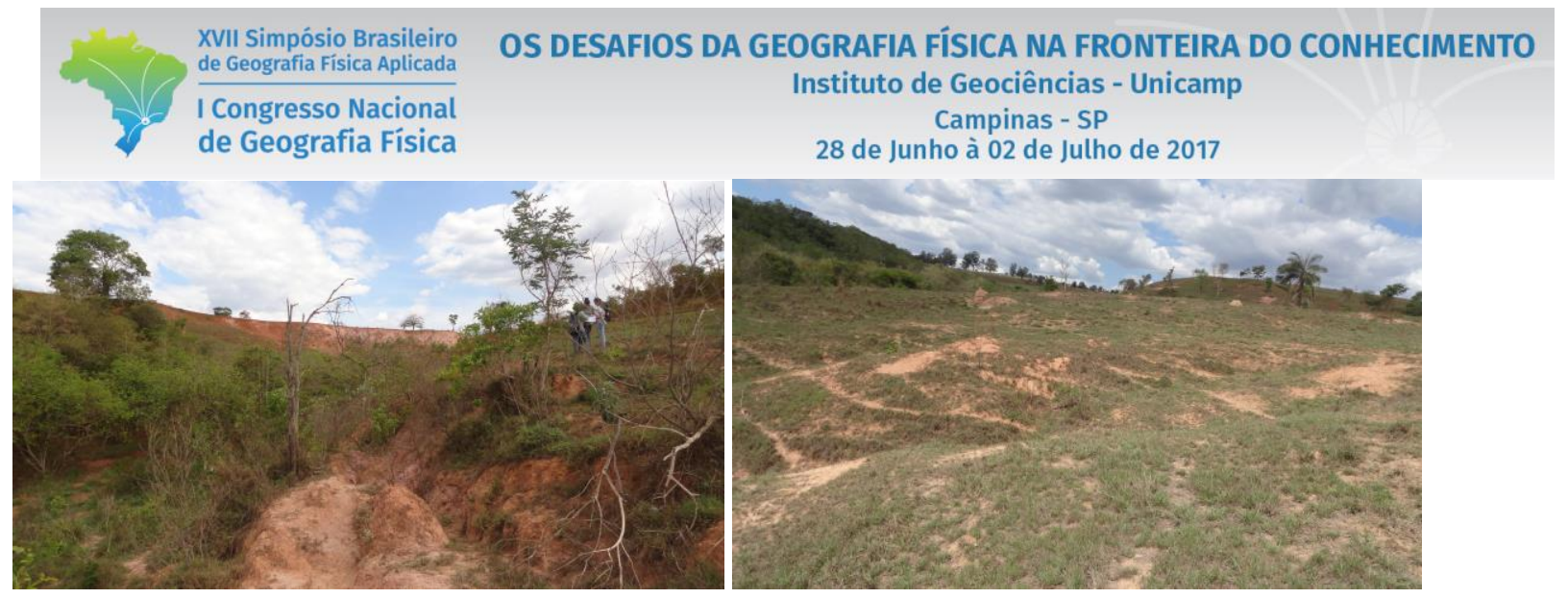

Foto 1: Voçoroca posicionada em cabeceira de drenagem.

Foto 2: Imediações a voçoroca com o nítido uso de pastagem e marcante pisoteio do gado.

Outra área destinada a APPs com intensa dinâmica de ocupação corresponde à área alagada, também posicionada em cabeceira de drenagem. Conforme registrado no quadro 2, esta área apresenta área de 0.02 $\mathrm{km}^{2}$, correspondendo a $2.17 \%$ das áreas de APP. A intensa dinâmica de uso mencionada nesta área alagada pode ser exemplificada pelas fotos 3 e 4, quando representam, respectivamente, os dias 25/10/16 e 09/11/16. Em um primeiro momento a área alagada que deveria conter vegetação de APP, é utilizada para pastagem, enquanto no segundo momento, tal área sofreu o revolvimento do solo, para posterior plantio de soja.
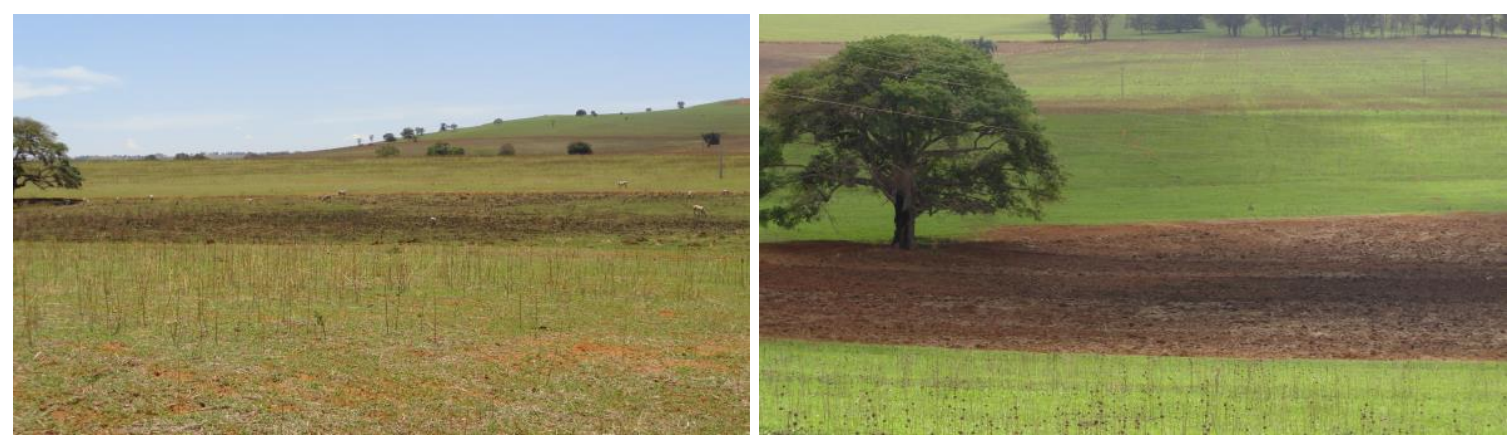

Foto 3: Área alagada em 25/10/16: presença do gado.

Foto 4:. Área alagada em 09/11/16: terra arada para recebimento de soja.

\section{Considerações Finais}

A partir da organização de um mapa de cobertura vegetal e uso da terra para as APPs de afluentes do ribeirão Limoeiro, bem como a partir dos trabalhos de campo na área investigada, pode-se observar que a retirada da vegetação contribui para a dinâmica erosiva. Reforça-se, portanto, a importância da manutenção das APPs, bem como das vegetações que extrapolam os limites jurídicos como contribuição a melhoria do manejo da terra, diminuindo assim os impactos causados pelos focos erosivos. 


\section{Referências Bibliográficas}

BRASIL Presidência da República. Lei Federal n. 3477, de 15 de setembro de 1965. Disponível em: < http://w.w.w .planalto.gov.ccivil-03/leis/1477/htm>. Acesso: 20 de setembro de 2016.

BRASIL Presidência da República. Lei Federal n. 12.651, de 25 de maio de 2012. Disponível em: http://www.planalto.gov.br/ccivil_03/_Ato2011-2014/2012/Lei/L12651.htm. Acesso em: 14 outubro de 2016.

IBGE, INSTITUTO BRASILEIRO DE GEOGRAFIA E ESTATÍSTICA. Censo 2010. Disponível em: <http://censo2010.ibge.gov.br/>. Acesso: 10 de outubro de 2016.

GOOGLE EARTH, Mapas. https://www.google.com.br/intl/pt-BR/earth/. Acesso em: 19 fev. 2017.

\section{Agradecimentos:}

Agradecemos o Instituto de Geografia (IG-UFU), o setor de Infraestrutura da Prefeitura Universitária UFU e o Grupo de Trabalho Técnico do Plano Diretor (GTTPD/UFU) pela oportunidade de realização desse trabalho.

Agradecemos o apoio da FAPEMIG que colaborou para a participação neste evento. 